\title{
A CONSTRUÇÃO DE UMA POLÍTICA DE COMUNICAÇÃO PASSANDO PELA REFORMULAÇÃ̃O ESTRATÉGICA DO PROCESSO DE GESTÃO E DA CULTURA DAS ORGANIZAÇÕES EDUCACIONAIS
}

\author{
Building a communication policy reformulation through the strategic \\ management process and culture of educational organizations
}

\section{Claudia Mara Vicentine}

Doutoranda pela Universidad Nacional de Misiones (UNAM), administradora de Empresas, Universidade da Indústria (Unindus), Curitiba, PR - Brasil, e-mail: cvicentine@gmail.com

\section{Resumo}

A alta competitividade do mercado faz com que toda organização promova um programa eficiente de comunicação e promoção. Partindo deste pressuposto, é necessário que sejam feitos estudos e análises dos instrumentos da comunicação em marketing, bem como das ferramentas promocionais que serão importantes para o processo no qual a organização, educacional ou não, está inserida. A comunicação é a base de sustentação da humanidade. As organizações vivem num cenário de oportunidades de mercado e num ambiente empresarial muito competitivo. Os elementos que caracterizam o fenômeno da globalização redefinem as formas e os métodos de competição e estratégia no mercado mundial, condicionam as decisões sobre alocações e uso de recursos e integram novas e ousadas estratégias empresariais. Atualmente não basta às empresas oferecer um excelente produto a um preço convidativo em locais de grande acessibilidade. Em função disso, é de vital importância analisar os aspectos dos atuais processos estratégicos de comunicação nas organizações.

Palavras-chave: Comunicação. Cultura. Marketing. Organizações.

\begin{abstract}
The highly competitive market makes every organization promotes an effective communication and promotion. Based on this assumption is necessary to make studies and analysis of the communication tools in marketing, as well to study promotional tools that will be important to the process in which the educational organization or is not inserted. Communication is the humanity support base. Organizations live in a setting of market opportunities
\end{abstract}


and a very competitive business environment. The elements that characterize the globalization phenomenon redefine the competition ways and methods and strategy in the global market, influence the decisions on allocations and resource use and integrate new and bold business strategies. Nowadays it is not enough companies to offer an excellent product at an affordable price in places of high accessibility. As a result, it is vital to analyze aspects of the current strategic processes of communication in organizations.

Keywords: Communication. Culture. Marketing. Organizations.

\section{INTRODUÇÃO}

A alta competitividade do mercado faz com que toda organização deva promover um programa eficiente de comunicação e promoção. Partindo desse pressuposto, é necessário que sejam feitos estudos e análises dos instrumentos da comunicação em marketing, bem como das ferramentas promocionais que serão importantes para o processo na qual a organização, educacional ou não, está inserida.

A comunicação é a base de sustentação da humanidade. Foi a partir dela que o homem se organizou em sociedade, vivendo em grupos. $\mathrm{Na}$ evolução humana, a comunicação contribuiu para o desenvolvimento e aperfeiçoamento da espécie, modificando em muito o comportamento do homem. No mundo contemporâneo surgem várias opções na forma de se comunicar, ou seja, no processo, que acabam afetando a relação entre o homem e meio ambiente.

Todos os indivíduos têm conhecimento e praticam a comunicação, apesar de nem todos conseguirem defini-la satisfatoriamente (já que o fazem com extrema naturalidade), seja esta comunicação efetuada por meio da linguagem seja a partir da simbologia.

Ao se iniciar com o conceito de comunicação, não se pode esquecer que este tem uma conotação interdisciplinar, ou seja, ele navega pela Sociologia, Antropologia, História, Psicologia, Linguística, Semiótica, Filosofia e outras disciplinas.

A compreensão da comunicação passa pelo conhecimento do processo de cultura dos indivíduos, que é uma das estratégias de transmissão e fortalecimento dos aspectos simbólicos que estruturam a dinâmica da comunicação.

A cultura é um fenômeno social que tem despertado o interesse de diversos pesquisadores, entre eles antropólogos, psicólogos e sociólogos.

Nas palavras de Vannucchi (2009), o conceito básico de cultura "é tudo aquilo que não é natureza, ou seja, tudo o que é produzido pelo ser humano. Por exemplo: a terra é natureza e o plantio é cultura. É o desenvolvimento intelectual do ser humano, são os costumes e valores de uma sociedade".

Já a comunicação é um fenômeno dinâmico mediante várias interpretações e diferentes correntes de pensamento. Churchil e Peter (2000, p. 449) definem comunicação como sendo a

[...] transmissão de uma mensagem de um emissor para um receptor, de modo que ambos a entendam da mesma maneira. Dessa forma, um anúncio impresso, um cupom, um comercial de televisão ou qualquer outra comunicação de marketing devem transmitir claramente o significado pretendido.

O homem é sabidamente um ser social que necessita estar em constante comunicação com seu semelhante, para que subsista em grupo e assim viva em harmonia. A comunicação é o meio pelo qual o homem consegue viver em grupo e seu instrumento é a linguagem. Essa comunicação ocorre por meio de um processo em que estão sempre envolvidos alguns elementos, também chamados de fatores, que serão abordados a seguir.

Observa-se que nem sempre o feedback será positivo. Afinal, trabalha-se com e para pessoas, logo, nem sempre se agrada a todos - mas em marketing não se deve desistir de fazê-lo!

O homem, na comunicação, utiliza-se de sinais devidamente organizados, e os emite a uma outra pessoa. A palavra falada, a palavra escrita, os desenhos, os sinais de trânsito são todos exemplos de comunicação, dos quais alguém se utiliza para transmitir uma mensagem à outra pessoa. No processo de comunicação têm-se os seguintes elementos: emissor, receptor, codificação, mensagem, meio, decodificador, resposta, feedback, além do ruído.

$\mathrm{Na}$ Figura 1 apresentam-se os elementos que representam o processo de comunicação: 
A construção de uma política de comunicação passando pela reformulação estratégica do processo de gestão e da cultura das organizações educacionais

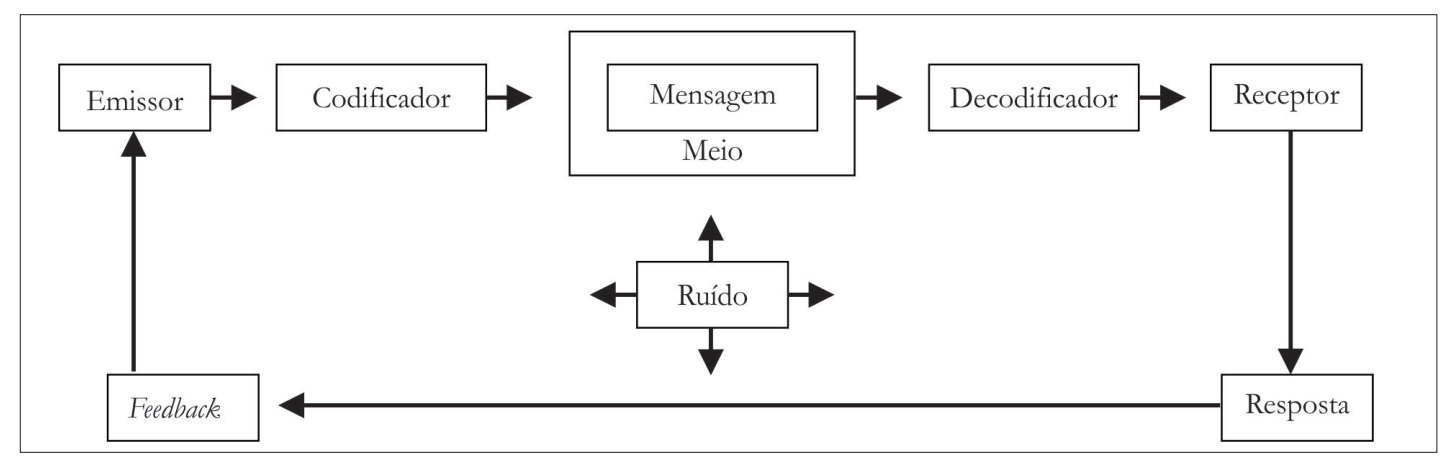

Figura 1 - Elementos no processo de comunicação Fonte: KOTLER; ARMSTRONG 1993, p. 289.

Faz-se necessário salientar o conceito de ruído, que, nas palavras de Kotlere Armstrong (1993, p. 289), pode ser entendido como a distorção não planejada durante o processo de comunicação, que resulta na obtenção de uma mensagem que chega ao receptor diferente da que foi emitida pelo receptor.

A comunicação se dá quando se tem efetivamente um emissor e o receptor. Já o ruído é tudo o que interfere no entendimento da mensagem, pois pode ser qualquer distorção que não permita o entendimento fiel e exato do que deve ser entendido por outras pessoas.

Conforme ilustrado na Figura 1, existem duas principais partes: o emissor e o receptor. Um ou ambos enviam uma mensagem através de uma mídia. Para comunicar-se de maneira eficaz, os emissores precisam conhecer as necessidades e desejos dos receptores. Os emissores devem ter habilidade de codificar mensagens que reflitam como a audiênciaalvo tende a decodificá-las. Eles devem desenvolver canais de feedback para que possam saber a resposta da audiência para a mensagem.

A comunicação tendo em vista as definições das estratégias anteriores é aquela em que se planeja o esforço de comunicação: os melhores meios para atingir cada um dos públicos previstos, o tipo de mensagem a ser utilizada, a frequência com que estas mensagens serão veiculadas, durante quanto tempo. O esforço de comunicação deve ser constantemente avaliado, para que se possa saber se os objetivos da comunicação estão sendo alcançados (REIS, 2004).

As organizações vivem hoje num cenário de maiores oportunidades de mercado, ao mesmo tempo em que o ambiente empresarial nunca esteve tão competitivo.

Os elementos que caracterizam o fenômeno da globalização redefinem as formas e os métodos de competição no mercado mundial, condicionam as decisões sobre alocações e uso de recursos e integram novas e ousadas estratégias empresariais.

Atualmente não basta às empresas oferecer um excelente produto a um preço convidativo em locais de grande acessibilidade. Cada vez mais, é necessário comunicar-se não só com seus clientes atuais e potenciais, mas também com os fornecedores, colaboradores, entidades de classe, investidores, ambientalistas, instituições de crédito, governo e público em geral.

Os novos métodos de trabalho e tecnologias, a concorrência global e a diversidade de ambientes políticos, econômicos e culturais exigem a concepção e práticas de novos conceitos e formas de gestão.

Esta realidade afeta todas as grandes áreas funcionais da empresa, desde finanças e recursos humanos até marketing e produção, além de todos os públicos relacionados, como clientes, acionistas, fornecedores, sindicatos e comunidade, entre outros. Toda e qualquer empresa assume o papel de comunicadora na sociedade, mesmo que não tenha clara consciência disso.

Diariamente, nos grandes centros, somos assolados por aproximadamente 1.600 mensagens comerciais (KOTLER, 1998, p. 528), sendo que dessas apenas 80 são percebidas de maneira consciente e 12 podem provocar algum tipo de reação, que nem sempre se revelará em compras efetivas. Percebe-se, então, que comunicar apenas não garante uma colocação competitiva diante do mercado e do consumidor.

Analisando parte dessas informações, nota-se o quanto é importante o cuidado com o desenvolvimento de comunicações eficazes que permitam dar conta dos objetivos organizacionais, 
que sejam suficientemente atrativas num turbilhão de informações e socialmente responsáveis e comprometidas com a verdade, de maneira que reforcem os propósitos emitidos pelas mensagens, criando uma imagem favorável.

Em função disso, é de vital importância analisar os aspectos dos atuais processos de comunicação nas organizações, sendo cada vez mais necessário que se estabeleçam ações sistemáticas e planejadas de comunicação para buscar a cooperação entre esses vários públicos de interesse da organização inclusive nas de cunho educacional.

Tradicionalmente, as empresas comunicamse por meio do chamado "composto de comunicação" ou "composto promocional". Parece-nos mais adequado composto de comunicação e não promocional, uma vez que a promoção é um elemento no processo total.

Constituindo-se em ferramenta estratégica, a comunicação precisa de administração planejada também para buscar maior integração no binômio competição-cooperação presente no atual contexto de mercado. E cada ação neste campo se constitui num desafio gerencial, por envolver públicos diferentes e elevado número de interfaces.

As organizações devem se preparar neste assunto com especial atenção, assim como o fazem em outras áreas da gestão moderna ou tradicional, pois a comunicação permeia, interfere e influi em todas as demais áreas.

O processo envolve o planejamento de ações sistemáticas que busquem facilitar o entendimento e conciliar o sempre presente potencial conflito de competição e cooperação entre as organizações e/ou públicos de interesse.

A comunicação utilizada de forma estratégica também permite expansão às organizações, por meio da busca de oportunidades, além de torná-las menos suscetíveis às instabilidades de mercado.

O composto comunicacional envolve a propaganda, e aqui se inclui também a merchandising, a promoção de vendas, as relações públicas, a venda pessoas e o marketing direto.

O planejamento e a administração estratégica da comunicação contribuem ainda para alavancar as oportunidades de mercadoe também amenizarou evitar possíveis ameaças externas, tais como crises, ações da concorrência, greves e pressões sociais, entre outras.

É por meio da administração da comunicação que se torna possível posicionar, estabelecer e manter uma relação de confiança e diferenciação da concorrência do mercado, especialmente com os clientes.

Todo comunicador deve conhecer seu público-alvo, afinal, este se constitui de compradores potenciais dos produtos da empresa, usuários atuais e influenciadores. Pode ser composto de indivíduos, grupos, públicos particulares, ou o público geral.

O público-alvo será fortemente afetado pelas decisões do consumidor sobre $o$ que será dito, como será dito e quemirá dizê-lo. Ao definir o mercadoalvo, o consumidor de marketing deve decidir qual resposta o público deseja. É claro que, na maioria dos casos, a resposta final é a compra.

A compra é o resultado de um longo processo de tomada de decisão do consumidor. $\mathrm{O}$ comunicador de marketing necessita saber em qual estado o público-alvo agora se encontra e para qual ele deve ser transportado.

A audiência-alvo pode estar em qualquer um dos seis objetivos da comunicação em marketing. Kotler e Armstrong (1993, p. 291) enumeram os seis estados de prontidão do comprador, descritos a seguir. Todo profissional de marketing deve utilizar-se de ferramentas da comunicação para atingir objetivos estratégicos bem específicos, que passam por:

a) consciência: criar consciência significa estar presente na mente do consumidor e isto leva um tempo;

b) conhecimento: o público pode ter consciência do seu produto, mas só isso; então a empresa deve pesquisar e verificar quantas pessoas conhecem e o quanto conhecem do(s) seu(s) produto(s);

c) simpatia: como o consumidor se sente em relação ao produto. Pode-se usar conceitos como "não gosta totalmente", "não gosta parcialmente", "indiferente" ou "gosta parcialmente". Ao se verificar algo desfavorável o comunicador deve descobrir por quê, então resolver os problemas para posteriormente refazer uma comunicação de comunicação visando a criar sentimento favoráveis;

d) preferência: o público-alvo pode gostar do produto, mas na hora da escolha opta por outro. Cabe, então, ao comunicador criar a preferência do consumidor, por meio da promoção da qualidade e demais aspectos do produto; 
A construção de uma política de comunicação passando pela reformulação estratégica do processo de gestão e da cultura das organizações educacionais

e) convicção: o público-alvo pode preferir o produto mas não desenvolver uma convicção quanto à sua compra. Neste caso, o comunicador deve criar a convicção de que o produto X é a escolha mais certa na hora da compra;

f) compra: alguns membros do público-alvo podem ter a convicção, mas não chegam a fazer a compra por 'n' motivos. Fica então ao encargo do comunicador, finalmente, levá-los ao passo final: a compra.

Ao se discutirem os estados de prontidão do comprador, assume-se que os compradores passam por estágios cognitivos (consciência e conhecimento), afetivos (gosto e preferência) e comportamentais (a compra), seguindo esta ordem.

A sequência de "aprender - sentir - fazer" é apropriada quando os compradores possuem alto envolvimento com uma categoria de produto e percebem marcas naquela categoria como altamente diferenciadas, como é o caso quando eles compram um produto tal como um automóvel. Porém, frequentemente os consumidores seguem outras sequências, por exemplo: "fazer-sentir-aprender", para elevado envolvimento com produtos com poça diferenciação percebida, ou "aprender - fazer - sentir", em que os consumidores têm pouco envolvimento e percebem pouca diferenciação, como é o caso quando compram um produto tal como o sal.

Compreendendo os estágios de compra dos consumidores e as sequências apropriadas, o profissional de marketing pode fazer um trabalho melhor de planejamento de comunicação.

Os estudos de competitividade valorizam o uso de recursos mais complexos de produção e de gestão dos negócios, fato este que levou as empresas a se alinharem com novos paradigmas. Entretanto, não se percebe ainda, com a profundidade necessária, a preocupação com a comunicação e seu planejamento de forma integrada para otimizar as possibilidades de alcance dos objetivos.

No mercado atual, que se caracteriza pela acirrada disputa dos produtos e serviços pela preferência dos consumidores, das empresas por participação de mercado e dos talentos por oportunidades profissionais, a diferenciação é imprescindível. O cliente é cada vez mais o centro das atenções, e estes buscam mais qualidade, rapidez e conveniência para fazer suas escolhas. Em função disso, a administração da comunicação eficiente se constitui no caminho para formar e consolidar os melhores conceitos para as organizações, seus produtos e serviços.

E ela se torna um conceito estratégico para a sobrevivência e o desempenho de uma organização, ao fornecer as melhores estratégias para favorecer o inter-relacionamento dos diversos públicos externos e internos, estabelecendo relação de confiança com os vários interlocutores organizacionais que se constitui em poderoso diferencial competitivo. Ser eficaz na comunicação é, sem dúvida, o desejo de todos.

Faz-se necessário elencar alguns passos que deverão ser seguidos para se obter o máximo de produtividade e qualidade da comunicação que se deseja, segundo Perez e Bairon (2002):

a) identificar o público-alvo: faz-se a análise do público a que será destinada a comunicação. Esse público poderá ser os clientes atuais, potenciais ou os influenciadores do processo de compra. Neste momento é importante conhecer a imagem atual em relação à empresa, seus produtos, marcas e até concorrentes;

b) determinar os objetivos da comunicação: trata-se de deixar claro o que se pretende com a comunicação que se está construindo. Os objetivos podem estar intimamente ligados à imagem ou ser absolutamente pragmáticos, como vender ou ampliar o market share (participação no mercado);

c) desenvolver a mensagem: as preocupações não apenas com o conteúdo da mensagem, mas também com a forma e a estrutura. Uma mensagem deve chamar a atenção, despertar o interesse, levar ao desejo e encaminhar à compra;

d) selecionar os canais: a escolha do canal, ou mídia, deve levar em conta o público a que se quer atingir, as características do canal (comunicação pessoal ou impessoal) e o orçamento disponível;

e) definir o orçamento: esta é uma das tarefas mais difíceis para as organizações na atualidade. Este método tem algumas vantagens: satisfaz os financeiros, que consideram investimentos em comunicação apenas como despesas, sem retorno; garante um investimento fixo em função das vendas reais, ou seja, leva em conta a disponibilidade da empresa; 
f) decidir sobre o composto comunicacional: decidir sobre as ferramentas que serão usadas e em que momento se deve fazê-lo é uma decisão absolutamente cuidadosa, pois tem que selevar em conta os objetivos organizacionais, o público envolvido e as melhores formas de utilização estratégica das ferramentas do composto;

g) mensurar resultados: é importante medir o resultado do impacto do plano comunicacional no público-alvo. Isto envolve pesquisa de mercado, questionando ao público se ele reconhece a mensagem ou se lembra dela, quantas vezes a viu e quais são os pontos de maior destaque, etc.;

h) administrar o processo de comunicação: a gestão do processo de comunicação envolve o reconhecimento do valor agregado de um plano abrangente que avalie todos os papéis estratégicos de toda a complexidade da comunicação: propaganda, promoção de vendas, marketing direto, etc., combinando essas ferramentas de modo aintegrar as mensagens, permitindo maior consistência, clareza e impacto da comunicação sobre o público-alvo.

De acordo com Neves (1998, p. 205) o objetivo da comunicação em marketing é construir um canal entre a organização e seus clientes, tanto os já conquistados ou em potencial e apresenta uma série de vantagens a partir da sua realização:

a) saberquemé ocliente/consumidor/usuário. Quais são as necessidades, hábitos e preferências, como se comporta e o que pensa da vida;

b) informar a este público da sua existência: empresa, produto, serviços, conceitos e diferenciais;

c) buscar um lugar ao sol (na memória do cliente);

d) saber sempre o que ele pensa a respeito da organização e de seus produtos;

e) defender-se rapidamente e com credibilidade, caso seja necessário;

f) construir uma relação de lealdade com o cliente/consumidor.

Assim como apresenta as vantagens para a organização a partir da observação e realização de um bom programa de comunicação, Neves (1998, p. 207) traz uma classificação para a comunicação de marketing e exemplifica conforme sua abrangência:

a) marketing de massa: caracteriza-se pela extensão da comunicação a um grande público;

b) marketing de segmento: nesta abordagem, o comunicador fecha o foco em cima de uma parte do grande público. O percentual de consumidores em potencial nesta abordagem é muito maior do que na abordagem de massa;

c) marketing de nicho: agora, o focoéainda mais reduzido. Um zoom é feito sobre o grupo de pessoas com uma, ou mais de uma, característica em comum;

d) marketing individual: o foco é fechado na pessoa, no consumidor em si.

Kotler e Fox (1994) afirmam que a grande maioria das instituições educacionais se utiliza das relações públicas ou da propaganda para difundir o seu processo de comunicação.

\section{Relações públicas}

A primeira empresaa terum departamento de relações públicas no Brasil foi a Light, em São Paulo, em 1914. Perez e Bairon (2002) observam que, de acordo com a Associação Brasileira de Relações Públicas,

entende-se por relações públicas um esforço deliberado, planificado, coeso e contínuo da alta administração para estabelecer e manter uma compreensão mútua entre uma organização pública ou privada e o seu pessoal, assim como entre uma organização e todos os grupos aos quais está ligada direta ou indiretamente.

Percebe-se aqui a importância das relações públicas para as organizações e cabe até afirmar sobre sua essencialidade nos planos de comunicação das organizações modernas.

Pinho (1990) salienta que o trabalho de relações públicas resulta, em longo prazo, na conquista da credibilidade e aceitação da instituição perante seu público-alvo, de maneira que assegure a criação e projeção de uma imagem institucional positiva e auxilie no alcance das metas de mercado. 
A construção de uma política de comunicação passando pela reformulação estratégica do processo de gestão e da cultura das organizações educacionais

Os praticantes de relações públicas veemse como responsáveis e enriquecedores da imagem da instituição. Em várias ocasiões são designados à tarefa de formar, manter ou mudar atitudes e nesta conexão são responsáveis por cinco etapas do processo (KOTLER; FOX, 1994, p. 324-325).

Todas as instituições educacionais estão envolvidas com relações públicas de alguma maneira, é o que afirmam Kotler e Fox (1994). Os mesmos autores dizem ainda que a comunidadelocal, políticos, mídias de notícias e outros - todos podem ter um interesse ativo ou reativo nas atividades da instituição.

\section{Propaganda}

Nas palavras de Nickels e Wood (1997, p. 323), propaganda "é qualquer comunicação paga e não-pessoaliniciada poruma empresaidentificada com o objetivo de criar ou continuar relações de troca com os clientes e, muitas vezes, com outros de interesse".

A propagandaé considerada não pessoal porque a mensagem não é entregue de uma pessoa a para outra, mas enviada por uma mídia como a televisão, o rádio, jornais, revistas, mala direta, internet e outdoors.

Esta é a característica que distingue a propaganda da venda pessoal e da comunicação oral, duas técnicas de comunicação integrada de marketing (CIM).

Para que se consiga desenvolver um programa eficaz de propaganda em uma instituição educacional, Kotler e Fox (1994, p. 338-339) sugerem que cinco importantes decisões sejam tomadas, as quais são apresentadas na Figura 2.

A Figura 2 representa as principais decisões a serem tomadas na administração de propaganda, pois esta, para ser eficaz, deve ter claros os objetivos a serem alcançados, quem será o público-alvo, o orçamento predeterminado, a mensagem que será veiculada devidamente avaliada e consequentemente as mídias específicas que serão usadas, e posteriormente deve ser feito uma avaliação da real eficácia da propaganda.

Kotler e Fox (1994) alertam para a definição dos objetivos da propaganda como parte fundamental para o alcance dos objetivos esperados. Estes objetivos, bem claros, devem fluir das decisões prioritárias definidas pela estratégia da instituição educacional, já que a estratégia de marketing global é que define o papel que a propaganda exercerá no composto de marketing total.

Em relação à mensagem, Kotler e Fox (1994) dizem que a sua geração envolve o desenvolvimento de diversas mensagens alternativas (apelos, temas, motivos e ideias) que são planejadas para obter a resposta desejada do mercado-alvo. Estas mensagens podem ser geradas de diversas maneiras; uma delas é por meio da conversa (entrevistas pessoais) com os participantes do mercado-alvo e outros influenciadores para determinar como veem a instituição ou o programa e quais são os seus desejos.

A seguir, o passo proposto por Kotler e Fox (1994) é a utilização de algum tipo de estrutura formal dedutiva para chegar-se às mensagens da propaganda. Esta técnica gera três tipos de mensagens: racional, emocional e moral:

a) mensagens racionais: objetivam passar uma informação adiante e/ou atender o autointeresse da audiência;

b) mensagens emocionais: visam a despertaralguma emoção positiva/negativa que motivará a ação;

c) mensagens morais: representam o que é certo e apropriado.

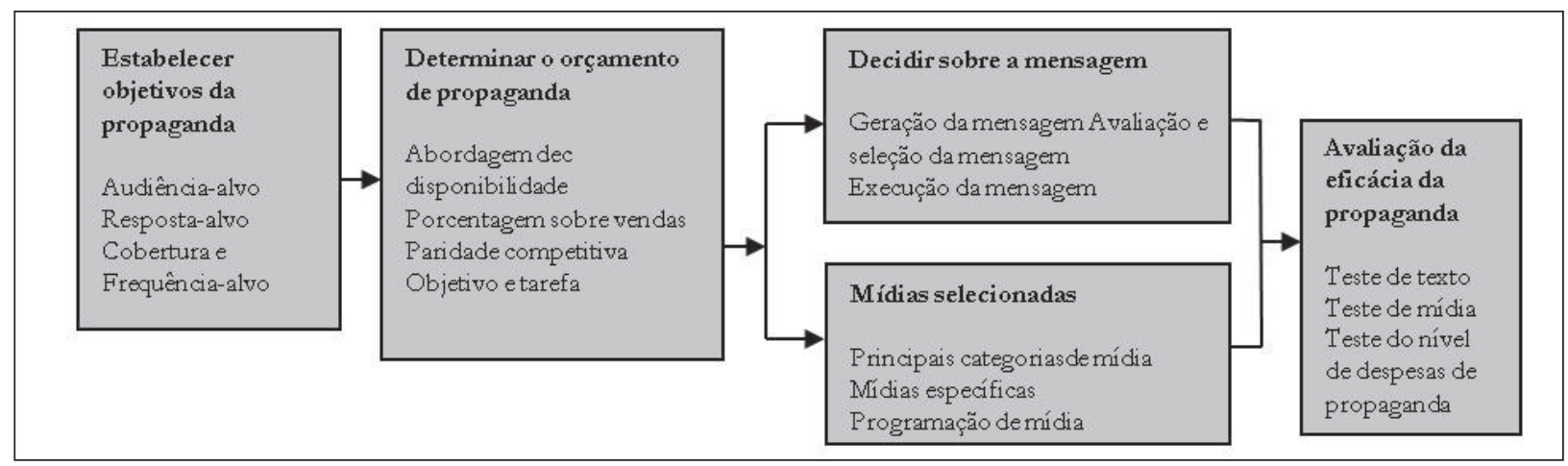

Figura 2 - Principais decisões sobre administração de propaganda

Fonte: KOTLER; FOX, 1994, p. 339. 
Kotler e Fox (1994) apresentam ainda um terceiro passo que examina as posições reais e desejadas do produto e analisa os temas que mudariam a visão do mercado para a direção pretendida. $\mathrm{O}$ anunciante pode tentar mudar a crença ou imagem sobre o nível do produto em algum atributo, a importância relativa percebida de atributos diferentes ou introduzir novos atributos geralmente não considerados pelo mercado.

Antes de selecionar a mensagem a ser utilizada pela instituição, Kotler e Fox (1994) sugerem que alguns passos devem ainda ser observados. Primeiro, a mensagem deve transmitir algo desejável ou interessante sobre o programa ou a instituição, entretanto, isto não é suficiente, já que a concorrência pode estar transmitindo as mesmas mensagens ou algo muito semelhante. Todavia, a mensagem deve também transmitir algo exclusivo ou distinto. Finalmente, ela deve ser confiável ou provável. Ao pedir para que consumidores avaliem diferentes mensagens em termos de desejabilidade e credibilidade, elas podem ser classificadas em termos de potência de comunicação.

Enfim, tem-se a necessidade de avaliar a propaganda realizada, de forma a colher informações que serão base para futuras decisões a respeito. O propósito de avaliar o efeito desejado pode ser realizado a partir de dois testes básicos (KOTLER; FOX, 1994, p. 357):
a) testes de lembrança;
b) teste de reconhecimento;
c) notaram;
d) viram/associaram;
e) leram mais.

Deve ser enfatizado que todos estes esforços avaliam a eficácia de comunicação do anúncio e não, necessariamente, seus efeitos sobre a atitude e comportamento do leitor ou usuário daquele veículo de comunicação. O efeito sobre a atitude é mais difícil de ser mesurado e deve ser feito após a realização da venda oudoserviço oferecido(KOTLER;FOX, 1994,p. 357).

\section{CONSIDERAÇÕES FINAIS}

A comunicação consiste no conjunto articulado de esforços, ações, estratégias e produtos de comunicação, planejados e desenvolvidos por uma IES ou instituição, com o objetivo de agregar valor à sua marca ou de consolidar a sua imagem junto aos públicos específicos, os acadêmicos, ou ainda, à sociedade como um todo. A comunicação, praticada com competência remete para um novo paradigma: a comunicação, ao marketing de uma IES.

As instituições de um modo geral já estão aprendendo a conhecer e utilizar corretamente o SIM para alcançar êxito e sucesso na captação e manutenção do alunado.

\section{REFERÊNCIAS}

CHURCHILLJR., G. A.; PETERJ. P. Marketing criando valor para os clientes. 2. ed. São Paulo: Saraiva, 2000.

KOTLER, P.; ARMSTRONG, G. Princípios de marketing. 2. ed. Rio de Janeiro: Prentice-Hall do Brasil, 1993.

KOTLER, P.; FOX, K. Marketing estratégico para instituições educacionais. 2. ed. São Paulo: Atlas, 1994.

KOTLER, P. Administração de marketing. 3. ed. São Paulo: Atlas, 1998.

NEVES, R. C. Imagem empresarial: como as organizações e as pessoas podem proteger e tirar partido do seu maior patrimônio. 2. ed. Rio de Janeiro: Mauad, 1998.

NICKELS, W. G.; WOOD, M. B. Marketing relacionamentos, qualidade, valor. 3. ed. Rio de Janeiro: LTC, 1997.

PEREZ, C.; BAIRON, S. Comunicação e marketing. 3. ed. São Paulo: Futura, 2002.

PINHO, J. B. Propaganda institucional. 2. ed. São Paulo: Summus, 1990.

REIS, L. G. C. Comunicação e marketing: noções gerais, conceitos básicos. Disponível em: <http: www. apc.org.br/gestao_teste/ge_testes/ge_mat01_marktxt0. cfm>. Acesso em: 13 out. 2004

VANNUCCHI, A. Conceito de cultura. Disponível em: <http://74.125.47.132/search?q=cache:KuJeoAGERkJ:pt.shvoong.com/books/1771321 conceitosc ultura $/+\% 22$ CONCEITO+DE+CULTURA $\% 22 \& \mathrm{~cd}=$ $3 \& \mathrm{hl}=\mathrm{pt}-\mathrm{BR} \& \mathrm{ct}=\mathrm{clnk} \& \mathrm{gl}=\mathrm{br}>$. Acesso em: 2 jun. 2009.
Recebido: 02/07/2009

Received: 07/02/2009

Aprovado: 10/10/2009

Approved: 10/10/2009 